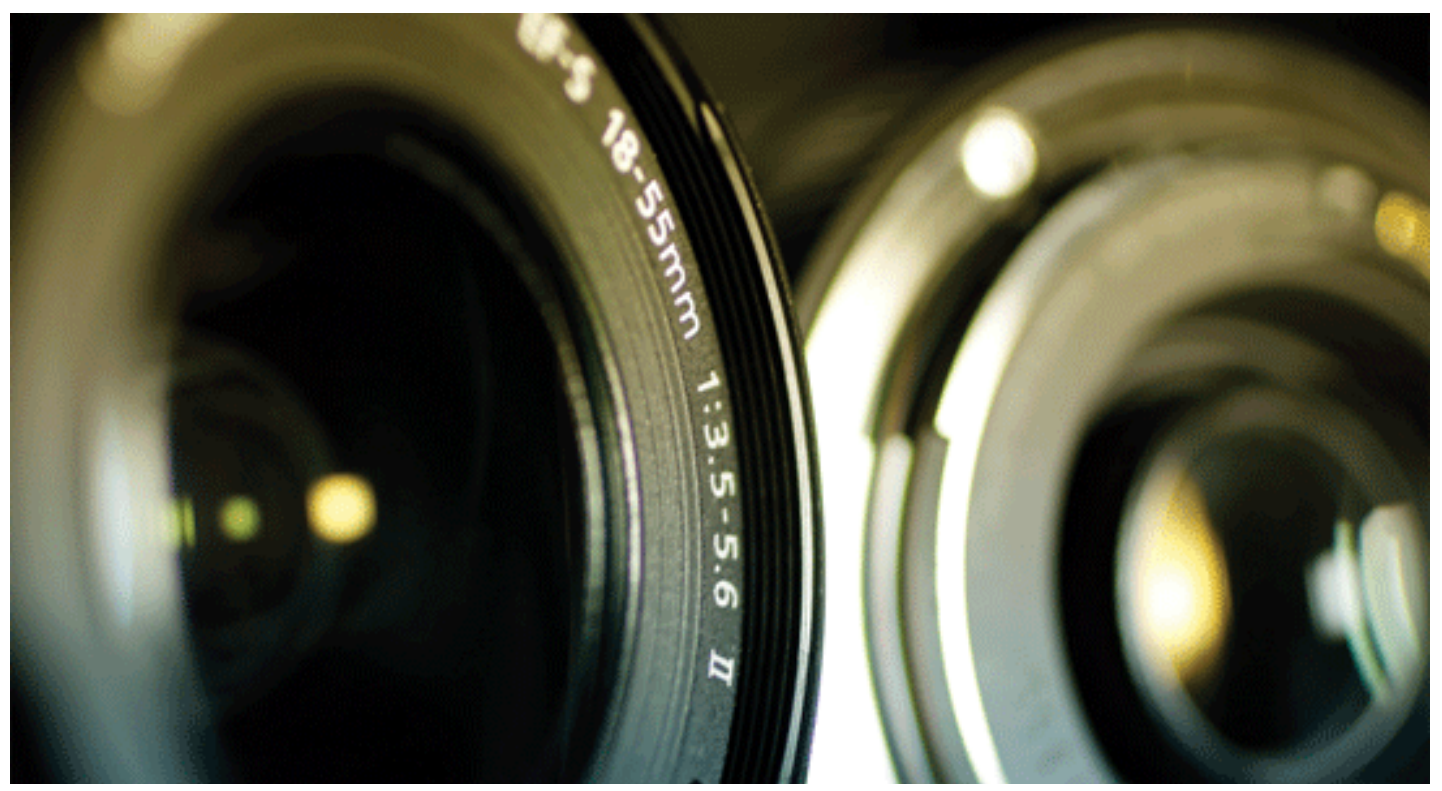

\title{
O que quer, o que pode um discurso? $O$ que quer, o que pode esta foto?
}

What a discourse want, what it can do? What this photography want, what it can do?

Viviane Teresinha Biacchi Brust ${ }^{*}$
Verli Petri ${ }^{* *}$

\section{Resumo}

O presente trabalho propõe reflexões sobre uma fotografia, colocando-a em relação à história e à memória do sujeito imigrante italiano da Quarta Colônia (RS), em um espaço urbano, para o que nos ancoramos na teoria do discurso, constituída por Michel Pêcheux e outros relevantes teóricos brasileiros. Embora o título de nosso estudo esteja construído com base em uma interrogação, não visamos a dar respostas, mas sim a percorrer caminhos de interpretação, propor possíveis percursos de leitura e análise.

Palavras-chave: discurso, sujeito, memória, história, interpretação

\section{Abstract}

The present work purpose reflections about a photography, put it in relation with history and with the subject italian immigrant of Quarta Colonia (RS), in a urban space, for what we tie on discourse theory, consist in by Michel Pêcheux and other relevant brazilian theoretics. Although the title of our study is built based on an interrogation, we do not aim give the answers, but traveling paths of interpretation, purposing possible routes of reading and analysis.

Keywords: discourse, subject, memory, history, interpretation

\footnotetext{
* Mestre em Estudos Linguísticos pelo PPGL/UFSM e doutorando pelo menos progrrama e instituição. Email: vivibrust@ hotmail.com; endereço postal: Caixa Postal 26 - CEP. 97.220-000 - Faxinal do Soturno - RS.

Pesquisadora Laboratório Corpus/PPGL/UFSM, professora DLV/UFSM, tutora do Grupo Pet Letras/UFSM. E-mail: verli.petri72@gmail.com
} 
A língua é minha pátria E eu não tenho pátria, tenho mátria

E quero frátria

(Caetano Veloso, Língua)

\section{Primeiras palavras}

Para intitularmos o estudo que ora empreendemos, encontramos, em alguns dos versos da canção Língua de Caetano Veloso, possibilidades de interpretação que nos levam a múltiplos caminhos e, com isso, a um espaço aberto para nosso (livre) pensar e, consequentemente, para o nosso parafrasear. "O que quer/ o que pode esta língua?" são palavras em versos e em canto que nos tomam pelos olhos, mas também por outros sentidos. Pelos olhos, a palavra escrita, a estrutura poética, os recursos de estilo, o paralelismo e a paráfrase, que troca o verbo querer pelo poder, deixando os dois à deriva... à deriva dos (outros e possíveis) sentidos, direcionados, depois, à questão da língua; pelos ouvidos, a palavra (en)cantada ${ }^{1}$, que, junto a instrumentos musicais que ritmizam para movimentar e desacomodar, traz, no seu tom, a ironia, o agridoce, do que agride e do que adoça, em forma de pergunta, jogando-nos também à palavra língua, acentuada ao extremo, pronunciada com a boca escancarada, para que seja, desse jeito mesmo, ouvida; pela pele, a tessitura do texto e a textura da voz, que nos toca e sensibiliza, colocando-nos na maciez de um berço-origem de/para pensar, enquanto nos embala/envolve para nunca nos deixar dormir. Se o poeta canta, referindo-se à "Flor do Lácio Sambódromo Lusamérica latim em pó”, brincando, sambando, misturando, metaforizando com as palavras, avaliamos que podemos, a partir de seu verso-pergunta, retomar as palavras que fez suas e dizer da nossa questão: o que quer, o que pode um discurso? e o que quer, o que pode esta foto? Para justificar esse exercício parafrástico, em que trocamos a palavra "língua" pela palavra "foto", sem deixar de passar pela/passar a palavra "discurso", ancoramo-nos na disciplina de interpretação denominada "Análise de Discurso", que vai ter sua fundação na França do final dos anos 1960 com Michel Pêcheux e continuidade no Brasil dos anos seguintes com Eni Orlandi e outros, também relevantes teóricos. É desse campo teórico-metodológico que nos embasamos para compreender língua e discurso, sujeito, história e memória. Nosso

\footnotetext{
${ }^{1}$ Interpretam a canção, além do seu compositor, Caetano Veloso, a cantora Elza Soares.
} 
objetivo final, depois de revisitar essas noções, é ler uma diferente materialidade discursiva, uma fotografia, à luz dessa teoria alicerçada no entremeio de três campos do saber, a Psicanálise, a Linguística e o Materialismo Histórico.

\section{O que pode a teoria do discurso?}

O termo língua é caro para todos que pensam a linguagem, de poetas e filósofos a linguistas e antropólogos. Para a Linguística, divisor de águas foi o Curso de Linguística Geral, publicado em 1916, a partir de cursos ministrados pelo linguista Ferdinand de Saussure. Como pontuam Gadet e Pêcheux (2004 [1981], p. 55), "Saussure constitui, direta ou indiretamente, a pedra de toque de todas as escolas linguísticas atuais, o seu ponto de partida crítico", seja pela definição de qual é o objeto da linguística, passando pelo seu conceito de língua - "um sistema de signos" -, diferenciado do conceito de fala - o qual fora preterido no decorrer de sua obra, exatamente pelo estudo da língua -, seja pelo seu conceito de signo linguístico, até o estabelecimento das dicotomias dele constitutivas e, essencialmente, a noção de valor.

Assim, é preciso entender, segundo Petri (2004), que Saussure, naquele momento, fez uma clara e objetiva exclusão das questões relativas à constituição do sujeito e do sentido na linguagem, higienizando o que compreendeu como objeto de estudo da Linguística, a língua, porque somente algo homogêneo, passível de análise interna, poderia sê-lo. Ao escolher a língua, que em sua concepção faz a unidade da linguagem, "Saussure excluiu o sujeito, elemento retomado somente bem mais tarde por outros teóricos do nosso século, no campo das Ciências de Formação Social, sobretudo, nos estudos da linguagem" (Ibid., p. 66). Assim, Michel Pêcheux, fundador da Análise de Discurso nos anos 60 do século XX, vai repensar essa questão - do mesmo modo como outros teóricos voltam a pensar a noção de sujeito da linguagem, embora sob outras perspectivas, a exemplo de Roman Jakobson, do Círculo Linguístico de Moscou (1915), e Émile Benveniste, nas décadas de 60 e 70 do século XX. E, como nos atesta Henry (2010 [1975], p. 26), "é justamente para romper com a concepção instrumental e tradicional da linguagem que Pêcheux fez intervir o discurso".

Embora o poeta que nos inspira dê - pelos versos "Gosto de sentir a minha língua roçar a língua de Camões" e "Gosto do Pessoa na pessoa/ Da rosa no Rosa" 2 - ao termo língua um recorte que antes aponta à língua que se abre à pluralidade cultural

\footnotetext{
${ }^{2}$ Fernando Pessoa (1888-1935) e João Guimarães Rosa (1908-1967)
} 
brasileira, a língua portuguesa ou língua brasileira, - e, com isso, talvez remetê-la ao conceito que leva ao objeto teórico da Sociolinguística - do que deixá-la sem qualquer apoio teórico, é pelo viés da Análise de Discurso que a pensamos, uma vez que, conforme Orlandi (2004a, p. 17), esta "se constitui na relação contraditória entre unidade e diversidade, contradição esta inscrita em seu próprio objeto já que não há como negar o fato de que há Língua e há Línguas, ou seja, há uma relação necessária entre o formalismo do sistema e a diversidade histórica concreta". É através dessa disciplina de interpretação que vai se instaurar um diverso modo de se pensar a Língua, ou seja, a língua, considerando o sujeito e definindo o discurso. Orlandi (2009, p. 22) explicita que a Análise de Discurso não trabalha com a dicotomia língua/fala no sentido de um par opositivo tal como o pensado por Saussure: faz, outrossim, um outro recorte teórico que relaciona língua e discurso. A língua, nesta concepção, não vai ser vista como algo totalmente fechado em si mesmo, sem falhas ou equívocos, enquanto o discurso também não é visto como algo destituído de condicionantes linguísticos ou determinações históricas. Pêcheux (2009 [1975], p. 81) afirma que "a língua se apresenta, assim, como a base comum de processos ${ }^{3}$ discursivos diferenciados", o que consiste em dizer que o uso do sistema linguístico não se dá de forma acidental. É importante salientar o que nos coloca o fundador da Análise de Discurso quando associa Linguística à Ciência das formações sociais, referindo-se à teoria histórica dos processos ideológicos e científicos:

[...] o sistema da língua é, de fato, o mesmo para o materialista e para o idealista, para o revolucionário e para o reacionário, para aquele que dispõe de um conhecimento dado e para aquele que não dispõe desse conhecimento. Entretanto, não se pode concluir, a partir disso, que esses diversos personagens tenham o mesmo discurso (Idem) [grifos do autor]

Esse, portanto, é o espaço construído pela Análise de Discurso, que, a partir de sua fundação, "marca sua singularidade por pensar a relação da ideologia com a língua, afastando a metafísica, trazendo para a reflexão o materialismo e não sucumbindo ao positivismo na ciência da linguagem" (ORLANDI, 2012, p. 37).

\section{a) Por uma possibilidade de resposta}

Partindo do que pensou Pêcheux nos anos 80, Petri (2005, [s.p.]) entende que o autor "nos convida a pensar sobre a necessidade de abertura das questões que são

\footnotetext{
${ }^{3}$ Grifo do autor.
} 
tratadas como puramente gramaticais, caminhando em direção à discursividade" e, ao retomar uma sua reflexão anterior, assim nos apresenta o discurso em relação à língua:

[...] o discurso aparece como o lugar onde se instalam as lutas que visam desconstruir pares opositivos do tipo gramatical/agramatical e possível/impossível da língua; é pelo discurso que se luta para que não se institua uma "única interpretação", "um sentido literal". É pelo discurso que se luta para que a sintaxe - enquanto superfície - não seja tomada como "plana", perfeita e bem delimitada, pois a cada aparição o discurso se revela como uma forma de sedução, na qual os efeitos de sentido entre os interlocutores podem ser sempre outros. É pelo discurso que se luta para que a língua seja considerada como elemento essencial, algo que está em pleno funcionamento, inalienavelmente, e só pode ser tomada em suas relações com o ideológico, com o social, com o inconsciente e com o histórico na materialidade discursiva (PETRI, 2006, p. 9).

Essas colocações já nos apontam para uma das possíveis respostas ao que pode a Análise de Discurso, a saber, colocar o discurso, na sua gênese, a relação entre sujeitos e sentidos, como algo passível de ser apreendido, pensado, analisado, desconstruído em suas evidências. Afinal, como bem refere Orlandi (2009, p. 22), "a linguagem serve para comunicar e não comunicar. As relações de linguagem são relações de sujeitos e sentidos e seus efeitos são múltiplos e variados". Conforme a autora (2005, p. 76-77), nessa teoria pensa-se a língua como fato e significa-se o que é social, ligando a língua e a exterioridade, a língua e a ideologia, a língua e o inconsciente. A língua passa a ser vista como uma estrutura não fechada em si mesma e sujeita a falhas. É quando se abre a possibilidade teórica de reintrodução do sujeito e, também por isso, amplia-se o campo dos estudos da linguagem.

A noção de sujeito é uma noção constitutiva da teoria do discurso, pois o sujeito, para se constituir (ou ser constituído), deve se submeter à língua, ao simbólico, ao jogo da língua na história, e o discurso é o que articula esse sujeito. Assim, pensar o sujeito é entender a proposta pechetiana de que o sujeito é parte constitutiva da língua pelo discurso que produz sentidos, afetado pelo simbólico. É preciso considerar também que Pêcheux elabora, dentro da sua teoria materialista do discurso, a noção de formação discursiva, a saber, "aquilo que, numa formação ideológica dada, isto é, a partir de uma posição dada, numa conjuntura dada, determinada pelo estado da luta de classes, determina o que pode e deve ser dito" (PÊCHEUX, 2009 [1975], p. 147), o que significa que o sentido das palavras, expressões, proposições dependem da formação discursiva na qual são produzidas. Afirmam ainda os autores (Id. Ibid.) que "os indivíduos são 'interpelados' em sujeitos-falantes (em sujeito do seu discurso) pelas

\footnotetext{
${ }^{4}$ Grifos do autor.
} 
formações discursivas que representam 'na linguagem' as formações ideológicas que lhes são correspondentes". Entendemos, com isso, por que uma palavra ou expressão não tem um sentido que lhe seja próprio. Para Orlandi $(2009$, p. 43), que reitera o conceito de Pêcheux para formação discursiva, é isso que vai explicar por que as palavras não têm sentido nelas mesmas e, outrossim, derivam seus sentidos das formações discursivas em que se inscrevem, representado no discurso as formações ideológicas que lhes correspondem. Isso quer dizer que "é pela referência à formação discursiva que podemos compreender, no funcionamento discursivo, os diferentes sentidos" (Id.Ibid.). Assim, as mesmas palavras podem significar diferentemente porque se inscrevem em formações discursivas diferentes, enquanto também pode ser possível que palavras, expressões ou proposições literalmente diferentes possam ter o mesmo sentido no interior de uma dada formação discursiva, quando então teremos os processos discursivos, entendidos como um sistema de substituições dentro dessa formação discursiva, conforme o que postula Pêcheux (2009 [1975], p. 148).

Somos levados a examinar, antes mesmo de entramos em especificidades do que se constitui o discurso, as propriedades discursivas da forma-sujeito, do eu imaginário, como sujeito do discurso. Nesse caso, Pêcheux (Ibid.) distingue duas formas de esquecimento no discurso: uma, o esquecimento da ordem da enunciação, o esquecimento $\mathrm{n}^{\mathrm{o}} 2$, que compreende que o dizer sempre poderia ser outro, o que formaria famílias parafrásticas, e que produz, em nós, a realidade do pensamento - uma ilusão referencial, quando haveria uma relação direta pensamento/linguagem/mundo; outra, o esquecimento ideológico, da instância do inconsciente, o esquecimento $\mathrm{n}^{\mathrm{o}} 1$, o qual resulta do modo como somos afetados pela ideologia, sendo que, por ele, temos a ilusão de sermos a origem do que dizemos quando, na verdade, retomamos sentidos já pré-existentes, além da questão de que os sentidos são determinados pela maneira como nos inscrevemos na língua e na história. De acordo com Orlandi (2009, p. 36), o esquecimento é estruturante, é parte constitutiva do sujeito e do sentido. Essas “ilusões", como as qualifica, devem ser entendidas como "necessidades para que a linguagem funcione nos sujeitos e nas produções de sentidos" (Id. Ibid.). Assim,

Quando nascemos os discursos já estão em processo e nós é que entramos nesse processo. Eles não se originam em nós. Isso não significa que não haja singularidade como a língua e a história nos afetam. Mas não somos o início delas. Elas se realizam em nós em sua materialidade. Essa é uma determinação necessária para que haja sentidos e sujeitos (ORLANDI, 2009, p. 35-36). 
Em outras palavras, quando sujeitos tornam-se sujeitos-falantes, há uma tomada de posição, a qual não deve ser concebida, de acordo com Pêcheux (2009 [1975], p. 160) como um "ato originário" do sujeito falante; ao contrário, deve ser compreendida como o efeito, na forma-sujeito, da determinação do interdiscurso, da exterioridade sobre si mesmo. Nesse sentido, Pêcheux (Ibid., p. 149) propõe chamar de interdiscurso "a esse 'todo complexo com dominante" ${ }^{5}$ das formações discursivas, esclarecendo que também ele é submentido à lei de desigualdade-contradição-subordinação que [...] caracteriza o complexo das formações ideológicas".

Orlandi (2009, p. 43) explicita que as formações discursivas podem ser vistas como regionalizações do interdiscurso, e, por sua vez, é ele, o interdiscurso, aquilo que disponibiliza os dizeres, determinando, pelo já-dito, aquilo que constitui uma formação discursiva em relação à outra. Diante disso, os sentidos não são predeterminados por propriedades da língua, ao contrário, dependem das relações constituídas nas/pelas formações discursivas. Além disso, reitera o que foi colocado anteriormente, ao dizer que "é preciso não pensar as formações discursivas como blocos homogêneos funcionando automaticamente. Elas são constituídas pela contradição, são heterogêneas nelas mesmas e suas fronteiras são fluidas, configurando-se e reconfigurando-se continuamente" (Ibid., p. 44).

Assim se trabalha com discurso - efeito de sentido entre os locutores -, e o discurso depende da ordem material da língua e da história para efetivar-se. A história existe como constitutiva do sujeito e do sentido, não sendo apenas fato exterior, como aspecto de complementaridade. Orlandi (2009) pensa a história também na sua relação com o interdiscurso, compreendendo-o como historicidade, como o que determina aquilo que, da situação, das condições de produção, é relevante para a própria discursividade. Segundo a autora, inscreve-se essa exterioridade no interior da textualidade.

Afirma Orlandi (2009, p. 33) que, "ao se pensar a relação da historicidade (do discurso) e da história (como se dá no mundo)", considera-se o interdiscurso como o lugar onde isso se especifica. Já Pêcheux (2007 [1983]), ao abordar as condições por ele entendidas como mecanismos e processos, entre outros, nas quais um acontecimento histórico - um elemento histórico descontínuo e exterior - é suscetível de vir a se inscrever na continuidade interna, no espaço potencial de coerência próprio a uma

\footnotetext{
${ }^{5}$ Grifos do autor.
} 
memória, também define como esta deve ser entendida. Para o autor, ela não pode ser apreendida como memória individual, "mas nos sentidos entrecruzados da memória mítica, da memória social inscrita em práticas, da memória construída pelo historiador" (Ibid., p. 49-50). Além disso, memória

[...] não poderia ser concebida como uma esfera plena, cujas bordas seriam transcendentais históricos e cujo conteúdo seria um sentido homogêneo, acumulado ao modo de um reservatório: é necessariamente um espaço móvel de divisões, de disjunções, de deslocamentos e de retomadas, de conflitos de regularização... Um espaço de desdobramentos, réplicas, polêmicas e contradiscursos (PÊCHEUX, 2007 [1983], p. 56).

Pêcheux (2008 [1983], p. 53) considera que sempre haveria um jogo de forças na memória, sob o choque do acontecimento: ora um jogo que visa manter uma regularização pré-existente com os implícitos que veicula, trabalhando com a estabilização e a integração do acontecimento até a sua eventual dissolução, ora o jogo de forças de uma "desregulação" que perturbaria a rede dos "implícitos". No entanto, explica ainda que há uma fragilidade no processo de inscrição do acontecimento no espaço da memória, uma dupla forma-limite: "o acontecimento que escapa à inscrição, que não chega a se inscrever; o acontecimento que é absorvido na memória, como se não tivesse ocorrido" (PÊCHEUX, 2007 [1983], p. 50). Nesses processos, entendemos a relação entre sujeito e inconsciente e sujeito e ideologia, uma vez que a língua é o lugar onde se materializam as leituras que esse mesmo sujeito faz do "real", filtrando-o, direcionando-o, recortando-o, construindo-o, refazendo-o. A partir disso é possível identificar a tomada de posição de um determinado sujeito. Além disso, pode a memória ser saturada, pode também ser lacunar, com eclipses, segundo Courtine (1999); todavia, Pêcheux (2008 [1983], p. 56) acentua a "marca do real histórico como remissão necessária ao outro exterior, quer dizer, ao real histórico como causa do fato de que nenhuma memória pode ser um frasco sem exterior".

\section{b) Por outra possibilidade de resposta}

Isso nos leva a considerar que estamos diante de outra possibilidade de resposta à nossa questão inicial: a ressignificação das noções de história e memória. Portanto, “compreender os modos de funcionamento da história/memória na produção dos sentidos observáveis nas relações entre diferentes práticas sociais” (PETRI, 2010, p. 67) 
torna-se tão relevante nesta disciplina de interpretação. Apreende-se, por todas as considerações anteriormente colocadas, que:

[...] a história não deverá mais valer pelo acúmulo de informações que consegue reunir ao longo do tempo, mas pelo efeito de sentido que os acontecimentos revelados produzem num determinado espaço sócio-cultural e numa determinada época (PETRI, 2006, p. 4).

Diante disso, que a história existe como constitutiva do sujeito e do sentido, não se aceita defini-la apenas como fato exterior, como aspecto de complementaridade. Já quanto à memória, salientamos que esta:

[...] desenvolve-se em um espaço próprio, que se construiu por relações entre seres que se significam e significam as relações que sustentam a própria existência deste espaço como espaço vivido/dividido com seus gestos de significação (ORLANDI, 2004b, p. 26).

Assim, no embate entre história e memória e, principalmente, no que colocamos anteriormente, de acordo com as concepções pechetianas, quanto à fragilidade dos processos de constituição - ou não - dessa memória, percebemos o quanto isso diz à questão da imigração em que estamos pensando: a memória é um espaço contraditório, múltiplo, fragmentado, elíptico. No recorte que trazemos, referente a situações que envolvem história e memória do sujeito imigrante italiano da/na Quarta Colônia ${ }^{6}$, enquanto há uma história oficial que circula, que não se rende aos eventos de uma história social, há uma outra memória, também social, que tampouco se rende, se entrega, quiçá resiste ao que (não) contam os livros; e há outra, ainda, que se apaga, aos poucos. Parafraseando e metaforizando o que coloca Petri (2010, p. 68), "há necessidade de apagar o diabo, o mal, a dificuldade, em prol do estabelecimento de uma história que inclui o menino deus, o bem, a facilidade”. Em nosso caso, talvez não nos refiramos a uma história/memória em que circulem imagens ligadas a deus ou ao diabo, mas a questões simbólicas passíveis de litígio, circunscritas àquilo que pode e àquilo que não pode se manifestar, se dizer, quando há o poder do Estado que se alterna entre autoritário e democrático, o que proíbe e o que aceita, aquele que tolera ou que valoriza. São espaços e tempos em que as questões se dizem referentes "ao funcionamento da história e da memória, a presença e o funcionamento de cada uma: a primeira [...] vinculada ao que é oficial [...]; já a segunda, funciona no dizer que produz sentidos [...]

\footnotetext{
${ }^{6}$ A "Quarta Colônia de Imigração Italiana" a que nos referimos situa-se no Estado do Rio Grande do Sul, região central, e assim é denominada por ter sido o quarto - também foi último - dos núcleos de imigração italiana no estado. Abrange o território compreendido hoje pelos municípios de Faxinal do Soturno, São João do Polêsine, Dona Francisca, Nova Palma, Ivorá, Silveira Martins (considerado o berço desta colônia), entre outros.
} 
(PETRI, 2010, p. 72). Ao retomar Davallon (2007, p. 26), para quem "a história resiste ao tempo; o que não pode a memória”, Petri (op. cit.) observa, porém, que ambas podem funcionar coladas uma à outra. É esse o espaço de tensão - distensão e retensão - que se estabelecem, observáveis nos movimentos de construção, desconstrução e reconstrução de monumentos a partir de fotografias, onde percebemos, da história, apagamentos e retomadas; da memória, fragmentações, lacunas, elipses, saturações.

\section{O que podem diferentes materialidades?}

Pêcheux (2008 [1983], p. 51) traz, para seu discurso, palavras de $\operatorname{Milner}^{7}$ (1982, p. 336), as quais dão conta de que "nenhuma língua pode ser pensada completamente, se aí não se integra a possibilidade de sua poesia”, para relacioná-las a reflexões que faz acerca da "relação entre os universos logicamente estabilizados e o das formulações irremediavelmente equívocas, investigando as relações do descritível e do interpretável ao mesmo tempo em que percorre as formas de se fazer ciência (...)" ${ }^{\prime 8}$. Diante disso, o autor explicita certas "exigências" relacionadas à maneira de trabalhar da Análise de Discurso, alicerçada nos gestos de "ler, descrever, interpretar". No entanto, para nós, o sentido dessas afirmações se completam quando Orlandi afirma que "parafrasearia esta afirmação dizendo que a língua não pode ser pensada sem a possibilidade de outras formas materiais significantes" (2012, p. 58). Reconhecendo a abertura do simbólico, a autora chama-nos à atenção que a língua, sujeita a falhas, pode ser pensada em relação a essas diferentes materialidades significantes, que também são/estão sujeitas à falha. Diante disso, trazemos à baila Courtine (1999, p. 15-16), porque ele entende que "mesmo que se coloque aqui em jogo a materialidade não-linguística de um documento fotográfico, é na ordem do discurso ${ }^{9}$ que ele se é produzido" - É dessa matéria que se constitui o nosso objeto analítico, ele é da ordem do discurso, ele é uma fotografia. E é a partir dela que se desencadeiam outros discursos, em outras e diferentes materialidades discursivas. Se isso, portanto, se dá na ordem do discurso, sabemos que dizem - ou até silenciam - alguma, pouca, muita ou outra coisa, coisas ao contrário, e, principalmente,

\footnotetext{
${ }^{7}$ Quando o autor faz referência à obra de Roman Jakobson, em seu artigo “A Roman Jakobson ou Le Bonheur par La Symétrie".

${ }^{8}$ Cf. ORLANDI, 1990, in: Nota ao leitor, na obra "O discurso: estrutura ou acontecimento", 5 ed. Campinas, SP: Pontes, 2008 [1983], p. 8.

${ }^{9}$ Grifo nosso.
} 
que seus dizeres não são meras mensagens a serem decodificadas; são, outrossim, efeitos de sentido produzidos em condições determinadas e que estão de alguma forma presentes no modo como se diz, deixando vestígios que o analista de discurso tem de apreender. Para isso, é preciso relacionar o dizer com sua exterioridade, as suas condições de produção, que pressupõem os sujeitos e as situações (ORLANDI, 2009).

Conforme Orlandi (Ibid.), o que se tem discutido hoje, ao se falar em diferentes materialidades significantes, é o espaço contraditório do desdobramento das discursividades, o qual tem a língua como real específico. Se não tivermos a língua como referência, não estaremos fazendo Análise de Discurso, e sim Semiologia ou Semiótica. Assim, segundo a autora, o ponto teórico de relevância está em que há textualização do discurso em diferentes sistemas significantes, os quais mostram suas especificidades e abrem-se para que sejam exploradas em profundidade suas consequências, inclusive teóricas. Portanto, para Orlandi (Ibid.), pode-se dizer, tendo como base os princípios de análise e de acesso ao objeto, tal como havia colocado Pêcheux, que, quando se trabalha com a materialidade discursiva da imagem ou da pintura, ou ainda de outras, não se abandona a relação com a língua. "É preciso compreender, para qualquer caso, a natureza da relação entre as diferentes formas materiais e a concepção de língua como colocada mais acima” (ORLANDI, 2009, p. 47). De qualquer forma, já entrando em questões metodológicas de como fazer para se trabalhar com objetos de outra materialidade significante, afirma a autora que a primeira exigência para se trabalhar com a materialidade discursiva é dar o primado ao gesto de descrição delas, o próprio da língua enquanto ordem simbólica. Petri (no prelo), nesses termos, pontua que:

Trabalhamos, então, da perspectiva de quem "lê" diferentes materialidades, sendo que essa leitura é algo em movimento e, pela mobilização das noções teórico-analíticas sobre um corpus, é algo que pode explicitar como se dão os processos de produção dos sentidos, viabilizando o que Orlandi designa como "compreensão", saindo do senso comum e adentrando a especificidade dos discursos analisados. [grifos da autora]

Com base na reflexão de Petri (Ibid.) sobre a metáfora do movimento pendular, formulada para tratar daquilo que fundamenta a metodologia da Análise de Discurso, começamos a apreender que é preciso um movimento permanente entre a teoria e a análise, pela necessidade, muitas vezes, que advém do próprio corpus que recortamos. Mas é preciso destacar ainda outra questão com que trabalha Orlandi (2012): uma coisa é o objeto teórico, o discurso; outra, são os nossos objetos de análise, os quais são 
muitos e de diferentes naturezas. Ao se eleger a dança como materialidade discursiva, por exemplo, sabe-se que não é um objeto novo. O que é novo "é o que podemos dizer sobre o nosso objeto, por causa da conjuntura histórica, das formas históricas de assujeitamento, da materialidade discursiva, das condições verbais do aparecimento da discursividade" (Ibid., p. 52-53). Embora estejamos tratando de fotografia, para ilustrar a questão teórica que vimos trazendo, buscamos em Orlandi suas reflexões acerca de uma estátua, a qual, inicialmente, nada colocaria à disposição de nosso estudo a não ser o fato de que tanto uma fotografia quanto uma estátua se constituiriam de outras materialidades discursivas. Porém, há um outro ponto, que consideramos um "ponto de encontro": uma estátua, assim como uma fotografia, trabalham com imagem, e imagem não é a "coisa em si”, mas sua representação, a sua imitação, a sua reprodução. Em uma, a imagem de monumentos; em outra, a imagem de uma figura da história. Diante disso, ressoa em nós o que Orlandi diz:

\begin{abstract}
Uma estátua, assim como qualquer objeto simbólico, que aqui tomamos como um discurso, não significa apenas em si. Todo sentido é "relação a" (Canguilhem, 1990). E, no caso de uma estátua, também os discursos a atravessam, os que ela produz - uma estátua não fala, mas produz discursos e que são parte de seus sentidos. É este o recorte que trabalhamos: o discurso da estátua de Fernão Dias e os discursos sobre Fernão Dias que a atravessam (ORLANDI, 2011, p. 15, grifo nosso).
\end{abstract}

É esse o olhar que lançamos a um dos nossos objetos de análise, uma fotografia. É preciso nos referirmos a ela, pois é através dela que vamos dispor de uma imagem, constituída de outra materialidade discursiva, e é ela que vai nos levar a monumentos. Davallon (2007 [1983], p. 27), ao refletir sobre a imagem, afirma que ela se constitui em um operador de memória social, explicando-nos, com isso, que imagens "permitem estocar depois restituir o saber quase tão bem quanto os acontecimentos" (Ibid., p. 23). Porém, faz-se necessário explicitar as justificativas para a nossa escolha, o recorte que fazemos de uma imagem, estática, solitária, pensando numa possível desproporção que possa parecer se instaurar entre uma simples e amarelada fotografia e grandes (considerando como maior grau de importância o maior alcance das mídias) ou extensos documentários, na direção de que a abordagem de Davallon faz referência aos arquivos das mídias: pois nossa imagem, pela fotografia selecionada, significa, primeiramente, dentro de um específico, quem sabe até restrito espaço político-histórico e social e tem importância porque mantém/faz permanecer uma memória dentro dele, a qual se relaciona, de alguma forma, com a história, a pequena e a grande história, em que pese 
também as condições de produção do discurso em distintos momentos. Assim, consideramos de igual relevância os dois discursos aqui colocados em paralelo. Daquele, nos diz Davallon, "saber" e "acontecimento"; desse, ecoamos nós: memória e história, que é local, mas constitutiva de algo muito maior.

O referido autor aponta, também, para o fato de que vai tomar a imagem sob um prisma particular: não pelo que ela pode representar, nem pela informação que pode oferecer, tampouco como objeto concreto de produção cultural, a levar em consideração sua eficácia simbólica. É sob uma outra abordagem, a de que "aquele que observa uma imagem desenvolve uma produção de significação; esta não lhe é transmitida ou entregue pronta" (Ibid., p. 28). Ao mesmo tempo em que isso se abre para uma liberdade de interpretação, atenta Davallon para a questão de que uma imagem também comporta um programa de leitura, assinalando um lugar ao espectador, como se houvesse um limite para as leituras. Para nós, inicialmente, isso poderia remeter a uma restrição à possibilidade de múltiplas ou de várias interpretações; porém, a apreensão de outro sentido levou-nos um pouco mais adiante: esse programa de leitura, de que trata o autor anteriormente citado, permite-nos compreender que, do lugar do espectador, junto à possibilidade de interpretações, não pode haver qualquer interpretação ou uma interpretação qualquer, pois a produção de sentidos está intimamente ligada à tomada de posição do sujeito.

Orlandi (2012), a respeito das colocações de Davallon, lança duas questões: a primeira, que não trataria imagem como operadora de memória social, mas como parte do funcionamento da memória discursiva com relação ao acontecimento; a segunda, quando questiona se a imagem se mostraria como ela se lê. Para a analista, "assim como qualquer materialidade significante, também a imagem não é transparente. É materialidade. Tem seu modo de funcionamento. Interpreta-se" (Ibid., p. 63). Diante da reflexão dos dois autores, um tanto diferenciadas entre si, propomos assumir uma posição de entremeio, já que ambas funcionam no interior do corpus que analisamos. É o movimento de realização das análises que coloca em funcionamento diferentes noções e para tratarmos disso retomamos as reflexões construídas a partir da metáfora do movimento pendular relacionada à análise discursiva, proposta por Petri [no prelo]:

Instalado o gesto de ler do analista no interior da discursividade que lhe interessa analisar, temos o pêndulo no ponto zero e daí começa o movimento. Por um instante, então, o analista suspende o pêndulo e imediatamente depois começa a acompanha-lo nas idas e vindas da teoria para a análise, perpassando de diferentes maneiras os elementos constitutivos do corpus, 
com sua opacidade, com suas resistências, com suas porosidades, com sua densidade, com sua incompletude constitutiva. É por tudo isso que o movimento é imperfeito, e, na maioria das vezes, imprevisível também. Há uma disposição inicial das posições, mas não uma garantia de chegada." (PETRI, 2012, no prelo)

Nesse sentido, olhando para o nosso objeto em suspenso, lançando-nos ao gesto de interpretação, perguntamo-nos: uma imagem, uma fotografia, que refere a um monumento, como funcionaria? Orlandi (2011, p. 22), em análise sobre a estátua de Fernão Dias, pontua: "uma estátua, como gesto de memória, de um Estado, é um discurso que individua. Que remete o sujeito a um processo de identificação, a uma posição-sujeito na sociedade". A referida teórica (2004a, p. 26), ao trabalhar o discurso urbano, diz que esse discurso, que tem uma memória, “desenvolve-se em um espaço próprio, que se constitui por relações entre seres que se significam e significam as relações que sustentam a própria existência desse espaço como um espaço vivido/dividido com seus gestos de significação". Com isso, nossa leitura, que tem um discurso constituído de outra materialidade discursiva, mas também discurso, comporta em si uma dimensão sócio-política que se articula ao simbólico.

Far-se-ia necessário, ainda, tocarmos em noções como a de territorialidade, mas, em função do que nos propusemos inicialmente, vamos apenas a ela nos remeter, uma vez que tal conceito não pode ser negligenciado, pois, segundo Orlandi (2011, p. 14), aliando-se cidade/sujeito/sociedade, há um enlaçamento significativo entre sujeito, espaço, linguagem e acontecimento. Ocupação - ou negação - do espaço social, significado aqui como praças e lugares públicos, diferenciados do espaço privado, espaço onde se estabelecem relações de poder e, desde que o poder está em jogo, também a possibilidade de intervenção, já que, pela sua definição jurídica, território é o espaço onde incidem leis, e, pela definição política, condição de terra que faz parte de um Estado (Ibid., p. 20). Nesse caso, os aparatos - estátuas, no estudo da autora e, no nosso caso, um monumento, referido pela imagem, pela fotografia - que estão a marcar território têm necessariamente de estar "consoante" às práticas territoriais do Estado, na medida em que este tem sua materialidade representada exatamente no território que ele define e em que poder e povo exercem/podem exercer/devem exercer sua soberania. Além disso, há a ideia de pertencimento, a qual envolve o sujeito individuado na sua relação com o todo de que é parte, segundo a mesma autora (Ibid.), quando também 
pode passar a ser um espaço de litígio, em que podem se confrontar - e se enfrentar sujeito individuado e Estado que individua.

\section{O que pode a fotografia?}

A fotografia sobre a qual tecemos algumas considerações neste trabalho é parte da constituição do corpus analítico de nossa dissertação de mestrado. Reproduz um bebedouro, construído em 1923, à beira de uma estrada, na localidade de Faxinal do Soturno, entre Nova Palma e Dona Francisca, quando, então, ainda não eram municípios e pertenciam, em sua maioria, à Cachoeira do $\mathrm{Sul}^{10}$. Em nosso trabalho, intitulado 'O chapéu de Clementis': imagens do sujeito imigrante italiano na/da Quarta Colônia, imagens - em diferentes materialidades - nos oportunizam percorrer um movimento que vai da posição-sujeito utopia à posição-sujeito político, passando pela posição-sujeito a que denominamos clivagem. Neste momento, destacamos a relevância de uma fotografia para se pensar a memória e a história constitutivas desse sujeito. Enumeraremos as fotografias para que a compreensão de nossa abordagem se torne mais clara, e o critério que usaremos para isso é o da ordem cronológica da imagem reproduzida:

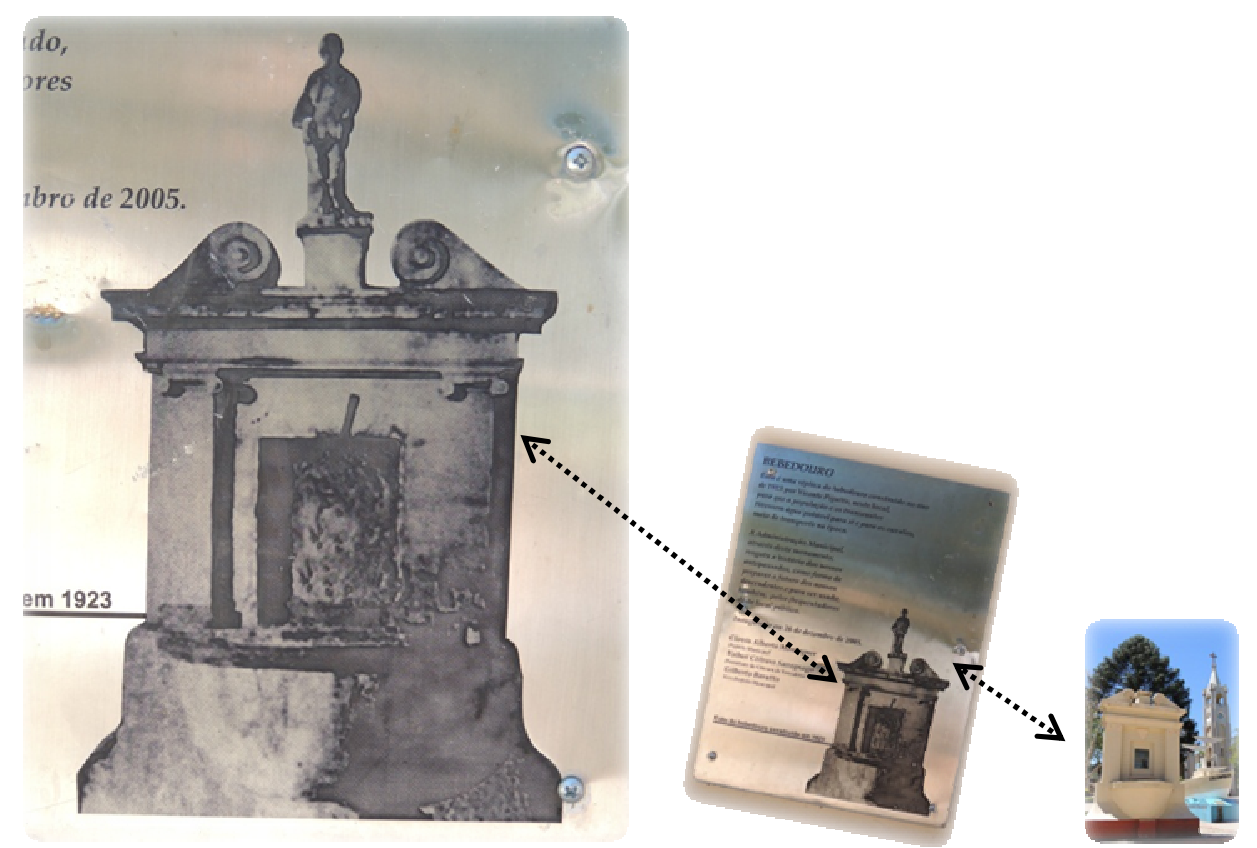

Foto 1

\footnotetext{
${ }^{10}$ Atualmente são municípios da região central do estado do Rio Grande do Sul.
} 
Foto 1: Reproduz a primeira fotografia do bebedouro construído em homenagem ao imigrante italiano, em 1923, em comemoração ao cinquentenário da imigração italiana na região ${ }^{11}$. Fonte: Arquivo pessoal.

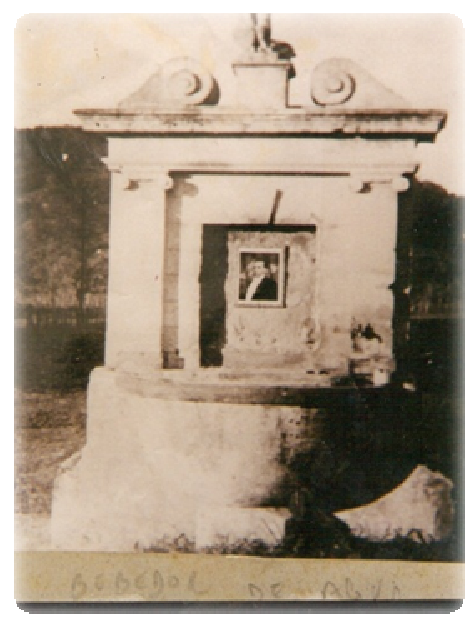

Foto 2

Foto 2: Também reproduz o bebedouro construído em homenagem ao imigrante italiano, em 1923, em comemoração ao cinquentenário da imigração italiana. ${ }^{12}$

Fonte: Secretaria de Obras do município de Faxinal do Soturno - RS

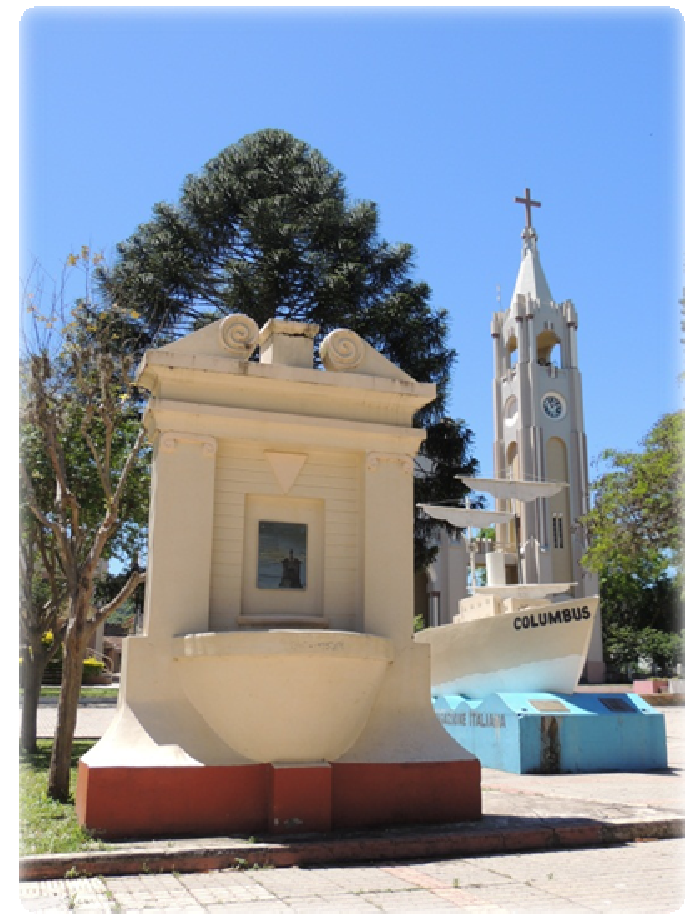

Foto 3

\footnotetext{
${ }^{11}$ Aquela que serviu para que se fizesse a reprodução não se tem mais.

${ }^{12}$ Tivemos acesso à reprodução dessa fotografia, não mais à original; esta foi a que nos instigou para a pesquisa
} 
Foto 3: Reproduz o bebedouro "reconstruído" pelo poder público, na Praça Vicente Palotti de Faxinal do Soturno, a partir da fotografia reproduzida na placa que se encontra ao centro. Primeira década do século XXI. Fonte: Arquivo pessoal

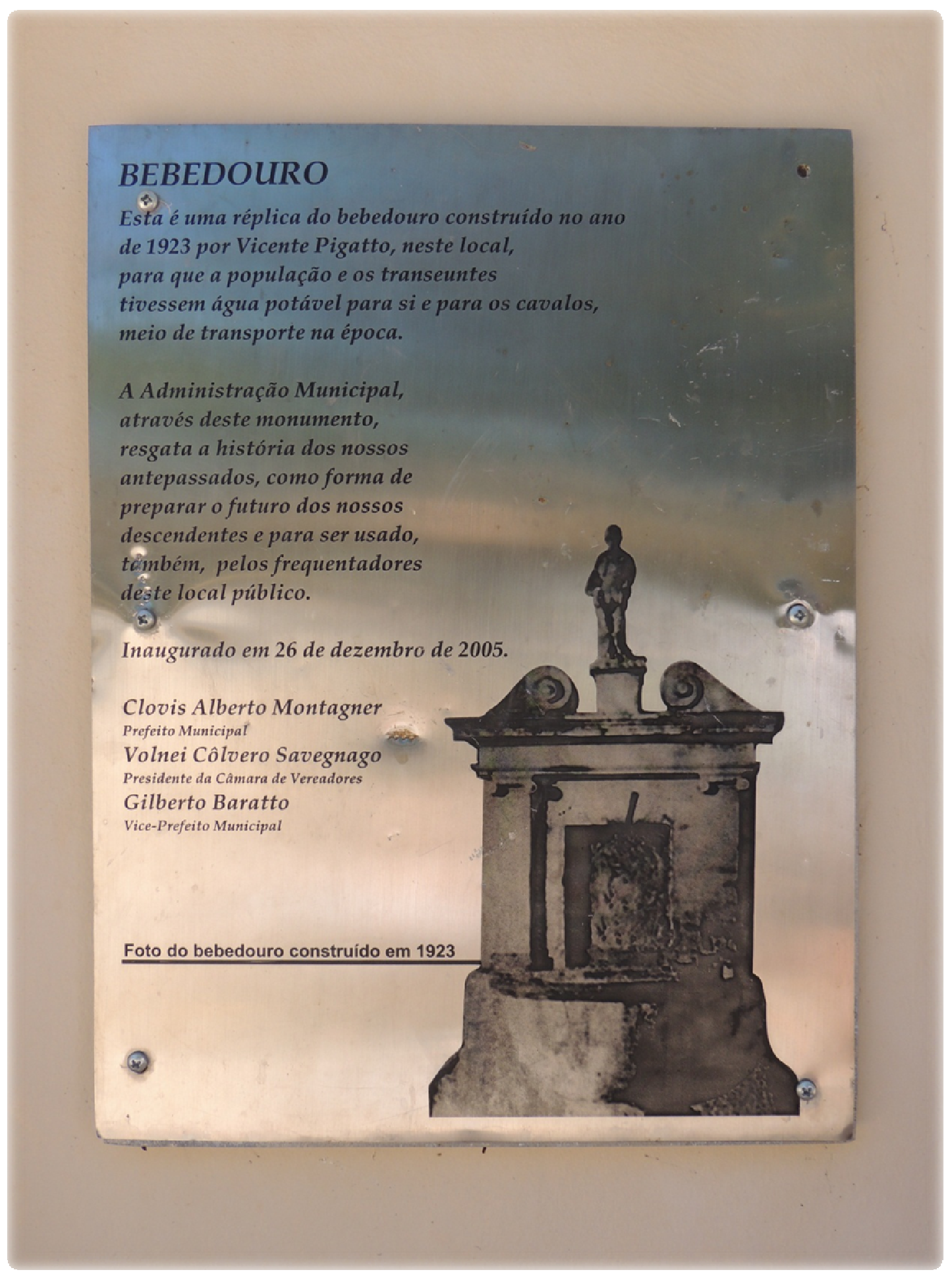

Foto 4

Foto 4: Reprodução da placa colocada ao centro do monumento referido na foto 3, réplica do monumento referido na foto 1 e 2 . Nesta placa, a reprodução da primeira foto do monumento. Fonte: Arquivo pessoal. 
Através dessas fotografias, as quais veiculam imagens, observamos que temos a língua em pleno funcionamento, pois estabelecem uma relação do sujeito com o social, com o ideológico, com o inconsciente e com o histórico. Nesta possibilidade de enxergar outras formas materiais significantes, produzimos, na/pela ordem do discurso, sentidos. É na relação com a sua exterioridade que passamos a nelas pensar. Essa imagem é tanto um operador de memória social, o qual estoca um saber e o restitui tanto quanto um acontecimento, como nos pontuou Davallon, anteriormente referido, quanto faz parte do funcionamento de uma memória discursiva, como nos explicou Orlandi, acrescentando a característica da sua não transparência. É através dessa imagem que sabemos desse imigrante - imigrante italiano na Quarta Colônia que quer significar-se, que quer pertencer, que quer delimitar/marcar território, da sua posição sujeito. Ele ocupa duplamente, contraditoriamente, um espaço público: o espaço geográfico de beira de estrada (marginal) e um espaço que é do poder público (central), o de levar água a quem dela precisa, sejam homens, sejam animais. Além disso, a memória oral coletiva dá conta de que, no lugar da fotografia que aparece no monumento (reiteradamente atribuída a Getúlio Vargas, a qual, até o momento, não conseguimos comprovar), havia uma placa escrita em língua italiana, para também, pela língua, ser feita a homenagem. Tal placa, antes de ser colocada, em seu lugar a foto de Getúlio Vargas, "desaparece" (conforme atesta a foto $\mathrm{n}^{\circ}$. 1). E há, no topo, a imagem de Santo Isidoro, imagem referida ao agricultor, ao lavrador, na/pela Igreja Católica - a que a maioria dos imigrantes se vinculava. Assim está o imigrante, social e historicamente simbolizado, ideologicamente constituído: no alimento e no trabalho, sobrevivência; na língua e na fé, a identidade, em um território previamente determinado: território geográfico, Quarta Colônia; território social: trabalhador. Mas a linguagem não é transparente, há discursos que se atravessam, mostrando um sujeito dividido: quem construiu e o que representa, se se coloca no poder de dizer do seu discurso o de todos os outros? Além disso, nas suas escolhas está a presença do político, no próprio ato metafórico de (se) simbolizar. Não seriam possíveis metáforas, monumentos, imagens outras?

Tal fotografia também traz a memória de um outro acontecimento: a interdição da língua italiana quando do Estado Novo (1937-1945). Novamente, não só a ausência da placa atesta tal acontecimento, como a memória coletiva também o referenda: ao produzir discursos outros, a ausência da placa alusiva ao cinquentenário da imigração 
diz da necessidade de sua retirada; outros discursos, da sua ocultação, do não saber - até hoje - onde está, uma vez que foi "enterrada" para que ninguém fosse vítima da violência de Estado $^{13}$. Cabe referir que, naqueles idos de 1937 a 1945, acontecia a Ditadura de Vargas, quando houve um processo de nacionalização dos imigrantes europeus no Brasil, o que se deu concomitantemente através da interdição das línguas maternas e da implantação do português nas zonas de colonização. Com medidas legislativas culturais e educacionais, os imigrantes foram convocados a abdicarem de suas línguas e, consequentemente de sua memória histórica. Zandwais (2007, p. 153) afirma que "é desta forma que se constrói, através da 'letra da lei', uma política de silenciamento, o antídoto contra a 'desnacionalização', ou, em outras palavras, a materialização da violência simbólica. Só assim poderão permanecer no interior da nação brasileira. Devemos acrescentar que tal interdição "não incide simplesmente sobre 'uma língua estrangeira', mas sobre sujeitos, sentidos e memórias presentes de modo central no seio da sociedade" (Payer, 2001, p. 242).

Além disso, o que esta fotografia significa como discurso é que ficou como a prova da existência de um outro discurso que fez parte do real da história, pois, mais tarde - não sabemos/não conseguimos precisar quando - por um motivo qualquer, segundo alguns, para "alargar" a estrada, o bebedouro foi destruído, porque não mais significava o que significava: parada obrigatória/necessária para se tomar água e descansar. Se não existisse a fotografia, a memória se perderia.

Na sequência, trazemos outra fotografia, a de $n^{\circ} .3$, que não é o referencial para o nosso estudo, apenas traz, para este espaço, pela imagem que apresenta, a réplica do monumento construído a partir da fotografia anteriormente reproduzida. Dessa materialidade, salientamos que o ato de reconstrução desse bebedouro, uma escolha, política e simbólica, só foi possível pela referência da fotografia primeira. Se aquela diz de como simbolicamente se representou, na década de 1920, o imigrante que ainda buscava a conquista de um espaço, pela língua, pelo seu imaginário, pela sua crença, pelo seu trabalho, hoje, século XXI, esta também o diz. Mas uma réplica não é o mesmo discurso. As condições de sua produção são outras, além da posição sujeito desse imigrante, que também é outra. Destacamos que, com essa "reconstrução", o Estado também quer se dizer outro, quer se ressignificar diante dos imigrantes, seus

13 Embora abordemos a violência simbólica, pela língua, houve violência física também. O artigo "Mordaça verde e amarela: imigrantes e descendentes no Estado Novo em Santa Maria e região", de Cátia Dalmolin (p.81-112, em obra homônima, publicada em 2005, pela Palotti), documenta alguns acontecimentos dessa ordem. 
descendentes e diante de toda a pluralidade étnica e cultural brasileira: é democrático, é pluricultural, é de/pelo direito. Esse mesmo imigrante, outrora interditado, se (re)constrói e ergue suas metáforas, profere seu discurso construído por outras materialidades em plena praça pública, pelo poder público que neste outro tempo acessa como cidadão brasileiro, com dizeres em língua portuguesa, sua moeda de negociação. Não mais Santo Isidoro, agora ausente, mas, ao fundo, uma igreja e outros tantos santos. Não mais a necessidade da água, mas a referência à história, pela memória, coladas. Não mais placa em italiano - nem fotografia de Getúlio Vargas (deste, há a reprodução de sua carta-testamento neste mesmo espaço público) - mas, em português, autorreferência e metalinguagem (monumento que fala de monumento). Não mais o apagamento, mas a reinscrição pela/na história. Espaço político, negociado, onde, na inscrição da placa, metonimicamente, não mais há espaço para "imigrante", apenas para “antepassados". Paráfrases e novo/outro significar?

De qualquer forma, para ambas as partes, é preciso suportar, se suportar, suportar o outro, o diferente. Afinal, refere Pêcheux (2009 [1975], p. 281): "não há dominação sem resistência: primado prático da luta de classes, que significa que é preciso 'ousar se revoltar'”, nem que tal resistência se dê pela imagem (re)produzida na/pela fotografia; a memória, suporta a história; porém a história, interdita, corta, para poder fixar a sua versão. Espaços de pensar e de significar onde ninguém ocupa o lugar do outro. Concordamos com Pêcheux (Ibid.): é preciso pensar por si mesmo.

\section{Palavras finais}

Remontando-nos às questões que, do cancioneiro de Caetano Veloso, dá início a nossas reflexões, somos tentados a formular respostas, pois, como já referimos, muitos são os caminhos que se abrem para este pensar. Todavia, este não é o espaço construído pela $\mathrm{AD}$, principalmente o de tentar verificar o que quer um discurso, até e principalmente porque o sujeito, tomado pelo inconsciente e sujeito à ideologia, tem somente a ilusão de poder e de domínio sobre a linguagem que o sustenta. Entretanto, para o que pode esta língua - e, principalmente, um discurso e esta ou outra fotografia desafiamo-nos a lançar algumas formulações, entre elas, que pode, sim, dar conta de um sujeito afetado pela língua e pelo simbólico que escreve, reescreve, descreve e se inscreve em uma história e em uma memória - a qual se materializa, pelo verso, pelo 
verbo, pela grafia da imagem..."E deixa que digam, que pensem, que falem", finaliza a voz da canção que não cessa de nos inspirar.

\section{Referências}

COURTINE, J-J. 1999. O chapéu de Clementis: observações sobre a memória e o esquecimento na enunciação do discurso político. Traduzido por M. R. Rodrigues. In: INDURSKY, F.; FERREIRA, C. L (Org.). Os múltiplos territórios da Análise de Discurso. Porto Alegre, RS: Sagra Luzzatto.

DAVALLON, Jean. 2007 [1983]. A imagem, uma arte de memória? In: ACHARD, Pierre et al.. Papel da memória. 2. ed. Traduzido por José Horta Nunes. Campinas, SP: Pontes.

GADET, F.; PÊCHEUX, Michel. 2004 [1981] A língua inatingível. O discurso na história da lingüística. Traduzido por Bethania Mariani e Maria E. C. de Mello. Campinas, SP: Pontes.

HENRY, Paul. 2010 [1975]. Os fundamentos teóricos da "Análise Automática do Discurso" de Michel Pêcheux (1969). In: GADET, Françoise; HAK, Tony (orgs.). Por uma análise automática do discurso: uma introdução à obra de Michel Pêcheux. 4. ed. Traduzido por Bethania Mariani et al. Campinas, SP: Ed. UNICAMP.

ORLANDI, Eni. 2012. Discurso em análise: sujeito, sentido, ideologia. Campinas, SP: Pontes.

2011. Os sentidos de uma estátua: Fernão Dias, individuação e identidade pousoalegrense. In: ORLANDI, Eni (org.). Discurso, espaço, memória: caminhos da identidade no sul de Minas. Campinas, SP: RG.

Pontes.

2009. Análise de Discurso: princípios e procedimentos. 8. ed. Campinas, SP:

2008 [1983]. Nota ao leitor. In: PÊCHEUX, M. O discurso: estrutura ou acontecimento. 5 ed. Traduzido por Eni Puccinelli Orlandi. Campinas, SP: Pontes.

SP: Pontes.

2005. Discurso e texto: formulação e circulação de sentidos. 2. ed. Campinas, 2004a. Cidade dos sentidos. Campinas, SP: Pontes.

2004b. Interpretação: autoria, leitura e efeitos do trabalho simbólico. 4. ed. Campinas, SP: Pontes.

PAYER, M. O. 2001. A interdição da língua dos imigrantes (italianos) no Brasil: condições, modos, consequências. In: ORLANDI, Eni (Org.). Historia das idéias lingüísticas: construção do saber metalingüístico e constituição da língua nacional. Campinas, SP: Pontes/UNEMAT. 
2009 [1975]. Semântica e Discurso: uma crítica à afirmação do óbvio. 4. ed. Traduzido por Eni Puccinelli Orlandi et al. Campinas, SP: ed. UNICAMP.

2008 [1983]. O discurso: estrutura ou acontecimento. 5 ed. Traduzido por Eni Puccinelli Orlandi. Campinas, SP: Pontes.

2007 [1983]. Papel da memória. In: ACHARD, Pierre et al. Papel da memória. 2. ed. Traduzido por José Horta Nunes. Campinas, SP: Pontes.

PETRI, Verli. 2012, no prelo. O funcionamento do movimento pendular próprio às análises discursivas na construção do "dispositivo experimental" da Análise de Discurso. In: DIAS, Cristiane; PETRI, Verli (Orgs.). Análise de Discurso em perspectiva: teoria, método e análise. Campinas, SP: Pontes.

2010. De "Garganta do Diabo" para "Vale do Menino Deus": reflexões acerca das práticas sociais e dos modos de designar o espaço público. Rua, n. 16, v. 1, Campinas, SP.

2006. Michel Pêcheux e a teoria do discurso nos anos 60. Conferência de abertura da Semana Acadêmica de Letras da UFSM. Santa Maria, RS: UFSM.

2005. Algumas reflexões sobre discursividade, gramática e sintaxe. In: INDURSKY, Freda; FERREIRA, Maria C. L. (Org.), Michel Pêcheux e a análise do discurso: uma relação de nunca acabar. São Carlos, SP: Claraluz.

PETRI, Verli. 2004. Algumas reflexões sobre o sujeito nos estudos da linguagem. Língua e Instrumentos Lingüísticos, $\mathrm{n}^{\circ}$ 13/14. Campinas, SP: Pontes.

ZANDWAIS, Ana. 2007. Saberes sobre a identidade nacional: o processo de construção de um imaginário de cidadania durante o governo Vargas. In: FERREIRA, Maria C. L.; INDURSKY, Freda (Orgs.). Análise de discurso no Brasil: mapeando conceitos, confrontando limites. São Carlos, SP: Claraluz.

Sites consultados:

www.caetanoveloso.com.br/discografia.php. Acesso em junho de 2012. 


\title{
Revista do Laboratório de
}

Estudos Urbanos do Núcleo

de Desenvolvimento da Criatividade

Para citar essa obra:

BRUST, Viviane Teresinha Biacchi; PETRI, Verli. O que quer, o que pode um discurso? O que quer, o que pode esta foto? RUA [online]. 2013, no. 19. Volume 1 - ISSN 1413-2109

Consultada no Portal Labeurb - Revista do Laboratório de Estudos Urbanos do Núcleo de Desenvolvimento da Criatividade

http://www.labeurb.unicamp.br/rua/

Capa: Autor desconhecido. Disponível em: http://www.revistagarimpocultural.com.br/wpcontent/uploads/2012/11/Fotografia.jpg

\author{
Laboratório de Estudos Urbanos - LABEURB \\ Núcleo de Desenvolvimento da Criatividade - NUDECRI \\ Universidade Estadual de Campinas - UNICAMP \\ http://www.labeurb.unicamp.br/ \\ Endereço: \\ LABEURB - LABORATÓRIO DE ESTUDOS URBANOS \\ UNICAMP/COCEN / NUDECRI \\ CAIXA POSTAL 6166 \\ Campinas/SP - Brasil \\ CEP 13083-892 \\ Fone/ Fax: (19) 3521-7900 \\ Contato: http://www.labeurb.unicamp.br/contato
}

